\title{
Feuer aus Feuerland
}

Liebe Leserin, lieber Leser,

„Was heißt denn Waldsterben? Zeig mir einen Baum, der gestorben ist, weil ich Porsche fahre. Ich zeige dir 100 PorscheFahrer, die sind gestorben, weil da ein Baum stand!" Natürlich war es die Sportwagenschmiede, die zur Zielscheibe des Kabaretts wurde, als die Umweltproblematik von Automobilen erstmals in den Fokus der Öffentlichkeit trat. Denn deren Produkte galten als Verkörperung der Dreckschleuder schlechthin: hoher Kraftstoffverbrauch, hoher Schadstoffausstoß.

Schon damals hätte so manchem Kritikaster ein differenzierterer Blick gut zu Gesicht gestanden. Aber ganz besonders wünscht man ihn heute jenen kurzsichtigen Mandatsträgern, die die Zukunft der Mobilität allein in Kombination mit elektrischen Antrieben sehen. Als letztes Mitglied im vermeintlichen Ökoclub hat Spanien ein Verkaufsverbot für Fahrzeuge mit Verbrennungsmotor ab 2040 verabschiedet und ist damit eines von rund einem Dutzend Ländern mit ähnlichen Beschlüssen. Auch wenn wir hier nicht müde werden, es zu erwähnen: Elektrofahrzeuge tragen nicht automatisch zum Klimaschutz bei, und per se umweltfreundlich sind sie schon gar nicht.

Überraschenderweise landen wir beim Stichwort „umweltfreundlich“ direkt wieder bei Porsche mit seinem Weitblick, sich an einem zukunftsträchtigen Unternehmen im Süden Chiles zu beteiligen. Dort, in der Nähe des berüchtigten Kap Hoorn, herrschen außergewöhnliche Windverhältnisse. Seeleute nennen diese Breitengrade nicht umsonst „brüllende Vierziger“ und „tosende Fünfziger“. Bei den Ureinwohnern Patagoniens heißt die Gegend „Hari Oni“, das bedeutet „Starker Wind“. Dies gab dem Projekt Hari Oni, an dem außer Porsche noch Siemens und Exxon beteiligt sind, seinen Namen und verweist auf die unerschöpflichen Reserven erneuerbarer Primär- energie. Dazu gibt es an den Gestaden des Atlantiks den ein oder anderen Tropfen Wasser. Ideale Voraussetzungen für die kostengünstige Herstellung grünen Wasserstoffs, der wiederum zur Produktion von E-Fuels verwendet wird.

Und genau das wird in Patagonien geschehen, und zwar schon bald. In der Pilotphase werden bereits 2022 etwa 130.0001 E-Fuel erzeugt. In zwei Schritten soll die Kapazität dann bis 2024 auf rund 55 Millionen 1 und bis 2026 auf circa 550 Millionen 1 pro Jahr gesteigert werden. Wie es aussieht, sorgt der Rückenwind aus Feuerland dafür, dass die Verbreitung eines ökologischen Kraftstoffs für Verbrennungsmotoren nachhaltig befeuert wird.

Möge es jenen Abgeordneten in den Ohren klingen, die ein Verbot von Verbrennungsmotoren beschlossen haben, wenn der erste Porsche mit eben solch einer Antriebsmaschine klimaneutral am Parlament vorbeigedonnert kommt, während dort noch jahrelang Elektrofahrzeuge mit Kohle-, Gas- und Atomstrom gefüttert werden.

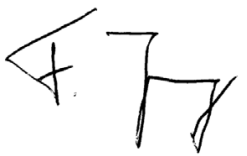

Frank Jung

Redakteur

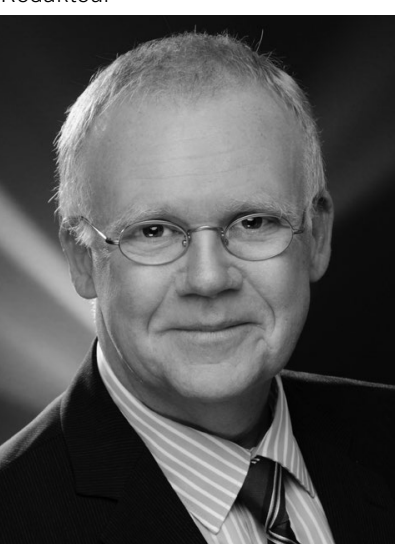

LEADING AUTOMOTIVE MAGAZINES IN ONE PACKAGE.
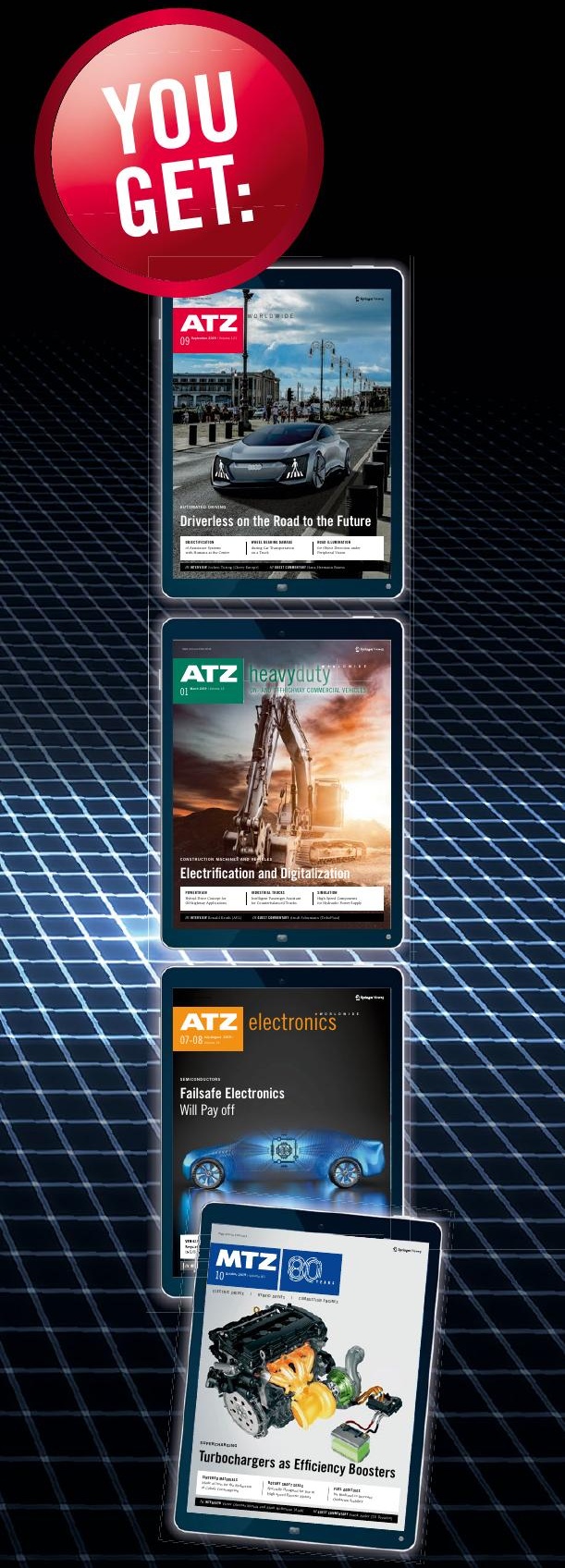

WATCH OUR VIDEO AND GET TO LEARN MORE: 